\title{
Starch functionalization of trimetallic W-Mg-Al oxide for oxidative desulphurisation of dibenzothiophene
}

\author{
Melody Kimi ${ }^{a^{*}}$, Zainab Ngaini ${ }^{\mathrm{b}}$ and Sinin Hamdan ${ }^{\mathrm{c}}$
}

${ }^{a}$ Centre for Pre-University Studies, Universiti Malaysia Sarawak, 94300 Kota Samarahan, Sarawak, Malaysia

${ }^{b}$ Department of Chemistry, Faculty of Science and Resource Technology, Universiti Malaysia Sarawak, 94300 Kota Samarahan, Sarawak, Malaysia ${ }^{c}$ Department of Mechanical Engineering, Faculty of Engineering, Universiti Malaysia Sarawak, 94300 Kota Samarahan, Sarawak, Malaysia

\author{
C H R O N I C L E \\ Article history: \\ Received October 30, 2019 \\ Received in revised form \\ November 21, 2019 \\ Accepted January 10, 2020 \\ Available online \\ January 10, 2019 \\ Keywords: \\ Oxidative desulphurization \\ Dibenzothiophene \\ Trimetallic oxide \\ Starch \\ Immobilisation
}

\begin{abstract}
A B S T R A C T
A novel trimetallic $\mathrm{W}-\mathrm{Mg}$-Al oxide composites immobilised onto starch were synthesized via sol-gel method. W-Mg-Al oxide composites were synthesized by first preparing $\mathrm{WO}_{3}$ using incipient wetness method, followed by immobilising onto $\mathrm{MgO}-\mathrm{Al}_{2} \mathrm{O}_{3}$ support using starch as binder. The effects of starch addition on the crystal properties and morphology were investigated by X-ray diffraction (XRD), Fourier Transform Infrared (FT-IR) spectroscopy and Scanning Electron Microscopy (SEM). In the presence of hydrogen peroxide and acetic acid as oxidant system, W-Mg-Al oxide starch composites exhibited higher catalytic performances for oxidative desulphurisation (ODS) of dibenzothiophene (DBT) at 95\% compared to W-Mg-Al oxide composites. The catalytic activity observed could be correlated to the distribution of active phases on starch as well as the higher crystallinity of the metal oxide composites.
\end{abstract}

\section{Introduction}

Sulphur-containing compounds in transportation fuels are one of the most undesirable contaminants, because they are converted to toxic sulfur oxides $\left(\mathrm{SO}_{\mathrm{x}}\right)$ through combustion. Studies have been conducted to reduce the sulphur content in oil fractions due to environmental regulation and concerns. ${ }^{1}$ Removal of sulphur-rich fuels such as benzothiophene and dibenzothiophene is crucial in the refinement of fossil fuels. ${ }^{2}$ Oxidative desulphurisation (ODS) operates in mild conditions overcomes the shortcoming of conventional hydrodesulfurisation (HDS) process which required high temperature and cost. Moreover, HDS is ineffective to remove aromatic sulphur compounds due to steric hindrance. ${ }^{3}$

In the ODS system, the thiophene compounds is oxidised to sulphoxides and/or sulphones using suitable oxidants such as hydrogen peroxide with acetic acid. ${ }^{4}$ High oxidant-to-sulphur ratio is required to oxidise sulphur compounds. The amount of oxidant used is reduced with the addition of catalyst.

* Corresponding author.

E-mail address: kmelody@unimas.my (M. Kimi)

(C) 2020 Growing Science Ltd. All rights reserved.

doi: $10.5267 /$ j.ccl.2020.1.001 
The ease of separation and stability for the heterogenous catalyst in the oxidation of sulphur prompt the use of transition metals loaded on support. For instance, Rezvani et al. reported the phosphotungestovanadate immobilied on PVA as reusable catalyst for oxidative desulphurization of gasoline in the presence of $\mathrm{H}_{2} \mathrm{O}_{2}$ showed impressive catalytic activity. ${ }^{5}$ Polar sulphur compounds produced by ODS is removed by polar solvent such as acetonitrile through extraction. ${ }^{6}$

$\mathrm{WO}_{3}$ has been applied in the ODS of fuel oil because of its thermal stability and good crystallinity. ${ }^{7}$ However, the catalytic performance and reusability of the bulk $\mathrm{WO}_{3}$ are limited due to their low specific surface areas which results in low active sites. ${ }^{8}$ These drawbacks can be avoided by dispersing $\mathrm{WO}_{3}$ on solid supports with high surface areas such as $\mathrm{WO}_{3}-\mathrm{Al}_{2} \mathrm{O}_{3}{ }^{9}, \mathrm{WO}_{3}-\mathrm{SiO}_{2}{ }^{9}$ and immobilising them onto an organic polymer ${ }^{7}$ to enhance the dispersion of catalyst on the support.

$\mathrm{Al}_{2} \mathrm{O}_{3}$ is an acidic oxide which promotes the adsorption of sulphur species. ${ }^{9}$ This would promote hydrogenation by protonation followed by hydride transfer in HDS. However, acid catalyst is prone to coking. ${ }^{11}$ The introduction of basic oxide, $\mathrm{MgO}$ onto $\mathrm{Al}_{2} \mathrm{O}_{3}$ prompts the acid-base interactions which would contribute to the highly dispersed sulphide species. Previous studies reported the same level or higher activities for $\mathrm{HDS}$ on $\mathrm{NiMoS} / \mathrm{MgO}-\mathrm{Al}_{2} \mathrm{O}_{3}{ }^{12}$ and $\mathrm{CoMo} / \mathrm{MgO}-\mathrm{Al}_{2} \mathrm{O}_{3}{ }^{13}$ catalysts compared with catalysts supported on $\mathrm{Al}_{2} \mathrm{O}_{3}$ only. It is expected that the addition of $\mathrm{MgO}$ to $\mathrm{Al}_{2} \mathrm{O}_{3}$ could improve the crystal and structural properties which could make them attractive as supports for $\mathrm{WO}_{3}$.

However, $\mathrm{MgO}$ suffers from instability when exposed under aqueous conditions. The addition of polymer is essential to improve its stability by acting as chelating agent. Addition of $\operatorname{starch}^{14}$ is increasingly common to control the growth of precipitated particles and to immobilise mixed metal oxides. The attached hydroxyl groups ${ }^{5}$ to the carbon chain can be a source of hydrogen bonding, which enhances the formation of polymer-based composite by binding to the surface. ${ }^{15}$ It was reported that the fine structure of starch also prevented aggregation of nanoparticles. ${ }^{16}$ Among the underutilized starches, sago starch has become popular largely because of the sustainability of the crop. ${ }^{17}$ Sago starch is produced from the trunk of sago palm (Metroxylon sagu) which is native to Southeast Asia. The prepared $\mathrm{WO}_{3}$ is added with sago starch as immobiliser to obtain good dispersion of the active sites onto the $\mathrm{MgO}-\mathrm{Al}_{2} \mathrm{O}_{3}$ support. Therefore, the objective of this study is to synthesis $\mathrm{W}-\mathrm{Mg}-\mathrm{Al}$ mixed oxide starch composite by sol-gel method and to elucidate the effect of starch on the properties of the mixed oxide. The nanocomposites catalytic activity will be evaluated in ODS reaction of dibenzothiophene (DBT) as model fuel with $\mathrm{H}_{2} \mathrm{O}_{2} / \mathrm{CH}_{3} \mathrm{COOH}$ as oxidant.

\section{Results and Discussion}

The FT-IR spectrum of starch is shown in Figure 1(a). The broad band in the $3700-3200 \mathrm{~cm}^{-1}$ regions can be attributed to the symmetrical stretching vibration modes of the adsorbed water molecules ${ }^{18}$ and several hydroxyl groups depicting the inter and intra molecular hydrogen bonding in starch. ${ }^{19}$ The FT-IR spectrum exhibited characteristic band for C-H stretching at $2933 \mathrm{~cm}^{-1}$ ascribed to the existence of hydroglucose group of the starch ring due to the $\mathrm{C}-\mathrm{H}$ vibration band. ${ }^{20}$

The other peaks are at $1647 \mathrm{~cm}^{-1}\left(\mathrm{O}-\mathrm{H}\right.$ bending of water in starch), $1461 \mathrm{~cm}^{-1}$ (C-H bending), $1366 \mathrm{~cm}^{-1}$ (angular deformation of C-H bond), $1162 \mathrm{~cm}^{-1}$ (C-O and C-C stretching), $981 \mathrm{~cm}^{-1}$ (skeletal vibration of a 1-4 glyosidic linkage (C-O-C), $928 \mathrm{~cm}^{-1}$ (C-C stretching), and $860 \mathrm{~cm}^{-1}\left(\mathrm{C}_{2}\right.$ deformation). ${ }^{21}$

The FTIR spectrum for W-Mg-Al oxide (Figure 1(b)) sample shows similarity to the spectrum of W-Mg-Al oxide starch (Figure 1(c)). This indicates that addition of starch did not change the composition and structure of the sample. A broad peak appears at below $1000 \mathrm{~cm}^{-1}$ for both samples, which corresponds to $\mathrm{O}-\mathrm{W}-\mathrm{O}$ stretching vibration in a monoclinic-type $\mathrm{WO}_{3}$ crystal. ${ }^{22}$ In Figure $1(\mathrm{~b})$ 
and $1(\mathrm{c})$, the band at $1643 \mathrm{~cm}^{-1}$ and $1632 \mathrm{~cm}^{-1}$ corresponds to $\mathrm{O}-\mathrm{H}$ bending of water, respectively. The peak at $1387 \mathrm{~cm}^{-1}$ for both samples indicates the $\mathrm{O}-\mathrm{H}$ in-plane deformation of oxalic acid residue used in the precursor. ${ }^{23}$

For W-Mg-Al oxide starch, the shift of the $\mathrm{O}-\mathrm{H}$ peaks of the composites from $3500 \mathrm{~cm}^{-1}$ to lower range from $\mathrm{W}-\mathrm{Mg}-\mathrm{Al}$ oxide is attributed to the interaction of the starch $\mathrm{O}-\mathrm{H}$ group on the surface of the W-Mg-Al oxide particles. The slight shift in FTIR spectrum is also reported when phosphotungestovanadate showed interaction on PVA support. ${ }^{5}$

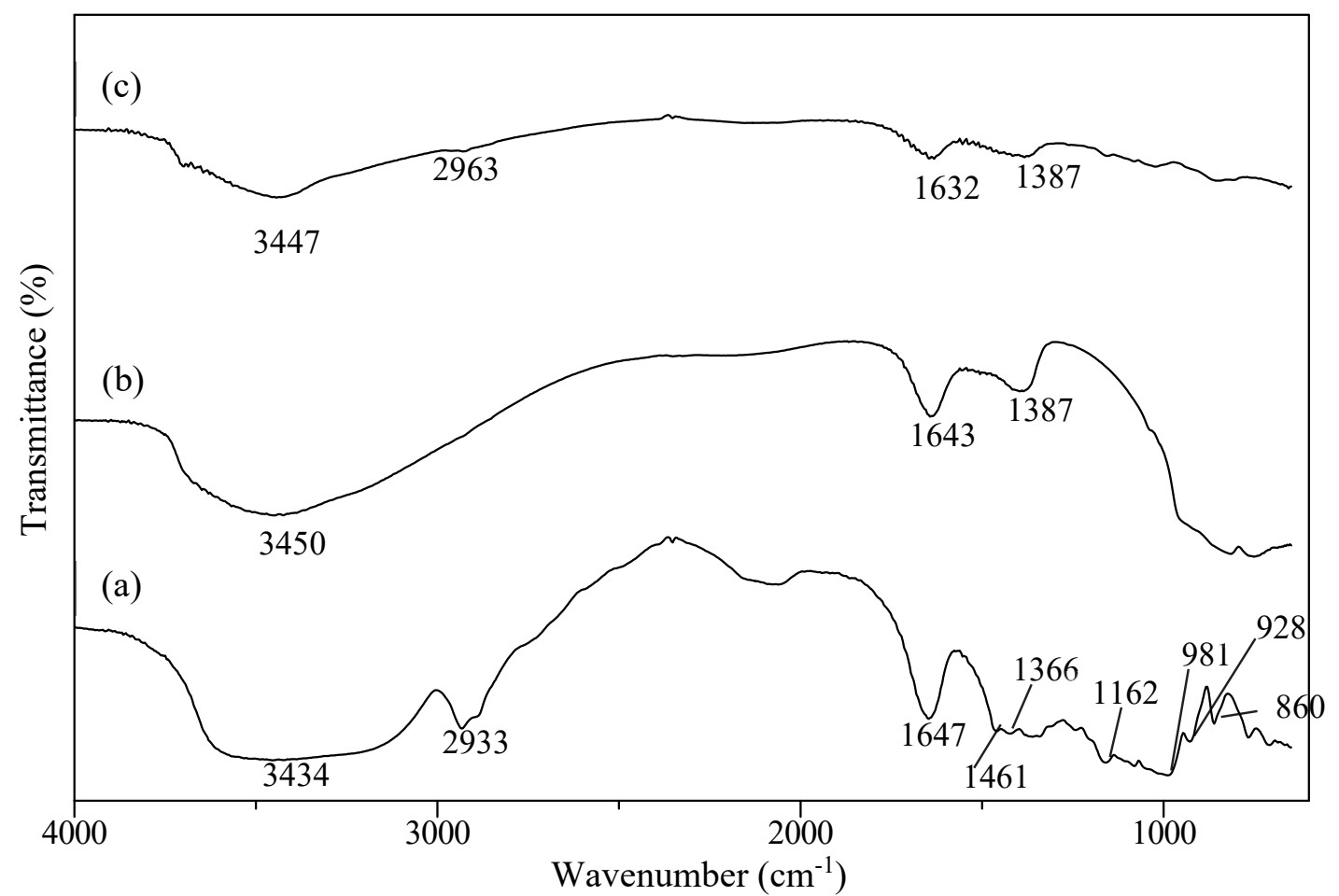

Fig. 1. FTIR spectra of the samples (a) starch (b) W-Mg-Al oxide and (c) W-Mg-Al oxide starch

The XRD analysis of the samples is shown in Fig. 2. The diffraction peaks of starch (Fig. 2(a)) are indexed to hexagonal carbon (PDF 00-050-0926). The peaks corresponds to $2 \theta$ with reflection planes at $14.8^{\circ}(110), 16.6^{\circ}(002)$ and $22.7^{\circ}(120)$. The low peak intensity shows that starch is in amorphous phase.

The diffraction peaks at $2 \theta$ with planes at $23.0^{\circ}(002), 23.5^{\circ}(020), 24.2^{\circ}(200)$ and $34.1^{\circ}(220)$ matched well with PDF 00-043-1035 of $\mathrm{WO}_{3}$ for $\mathrm{W}-\mathrm{Mg}-\mathrm{Al}$ oxide and $\mathrm{W}-\mathrm{Mg}$-Al oxide starch. This proves that the primary structure for this trimetallic oxides is monoclinic $\mathrm{WO}_{3}$ with high purity. ${ }^{24}$ No diffraction peaks for crystalline phases of $\mathrm{MgO}$ and $\mathrm{Al}_{2} \mathrm{O}_{3}$ are observed. This suggests that $\mathrm{MgO}$ and $\mathrm{Al}_{2} \mathrm{O}_{3}$ are highly dispersed in the matrix. It is obvious that the addition of $\mathrm{MgO}$ and $\mathrm{Al}_{2} \mathrm{O}_{3}$ does not change the crystal structure of $\mathrm{WO}_{3}$. The diffraction peaks corresponding to starch was not observed in $\mathrm{W}-\mathrm{Mg}$-Al oxide starch due to the low intensities of the starch peaks compared to the diffraction peaks of $\mathrm{WO}_{3}$. The absence of starch diffraction peaks might also due to the completely dissolved starch molecules in the mixed oxides. ${ }^{25}$ Similar observation was also recorded for $\mathrm{ZnO}$-starch nanocomposite prepared by Ma et al. ${ }^{25}$ It was observed that the addition of starch did not change the composition and structure of monoclinic $\mathrm{WO}_{3}$ in $\mathrm{W}-\mathrm{Mg}-\mathrm{Al}$ oxide starch sample. There was an increase in peak intensities when starch was added to $\mathrm{W}-\mathrm{Mg}-\mathrm{Al}$ oxide. This suggests that the crystallinity of $\mathrm{W}-\mathrm{Mg}-\mathrm{Al}$ oxide increased with the addition of starch. The trend in increasing crystallinity with the addition of starch was also observed when appropriate amount of starch was added into layered double hydroxides (LDH). ${ }^{18}$ However, excessive starch addition would reduce crystallinity of LDH. This suggest that the starch amount added in this study is sufficient. 


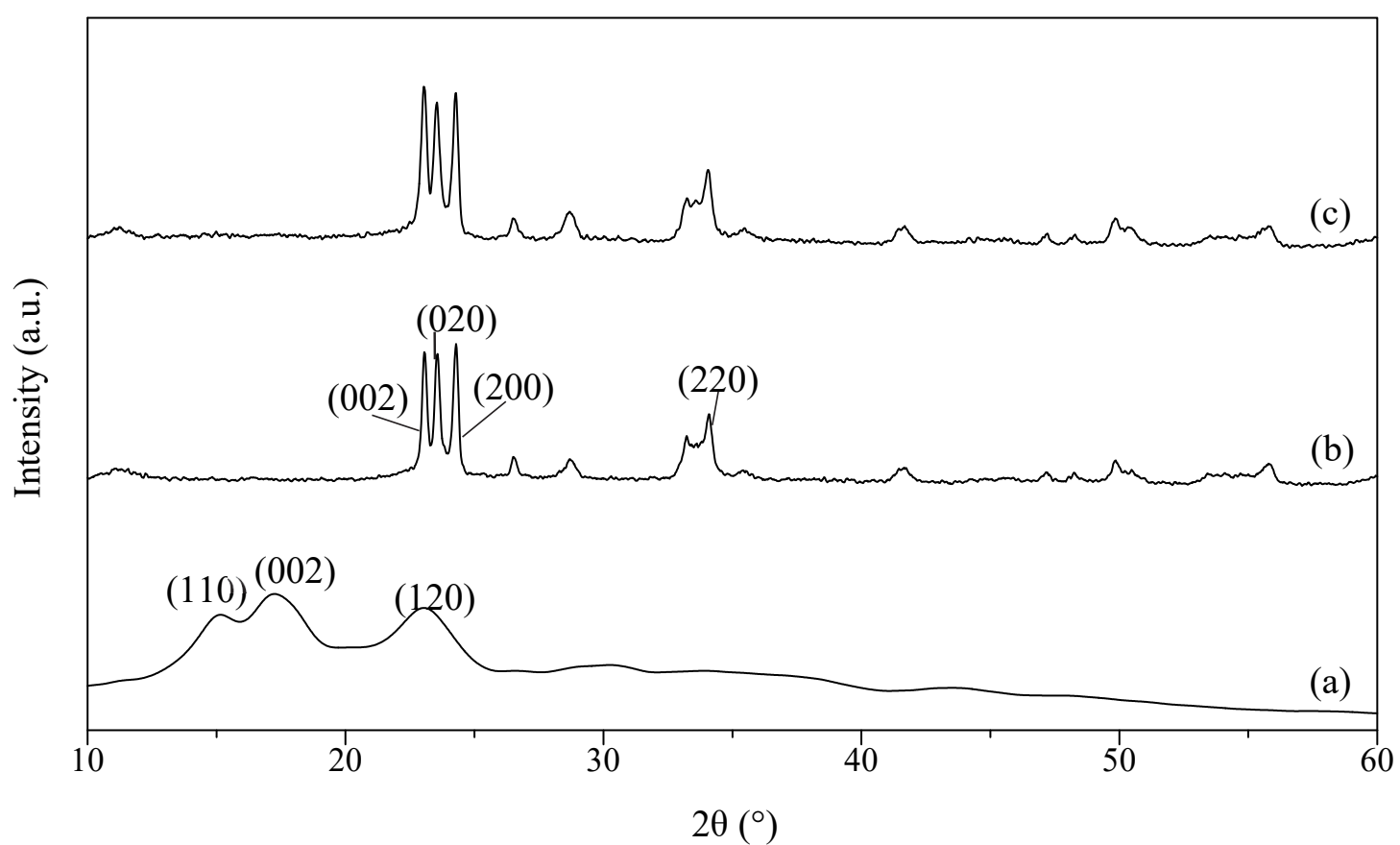

Fig. 2. XRD pattern of the samples (a) starch (b) W-Mg-Al oxide and (c) W-Mg-Al oxide starch

The crystallite size of the as-prepared samples calculated using the Scherrer equations from XRD data, are presented in Table 1. Detected phases are observed in the micro size scale. The crystallite size for starch using the (120) reflection was estimated to be $5.6 \mathrm{~nm}$. The huge differences of the crystallinity between starch and metal oxides influenced their crystallite size. The crystallite size for W-Mg-Al oxide and W-Mg-Al oxide starch using the (200) reflection were estimated to be $38.7 \mathrm{~nm}$ and $39.3 \mathrm{~nm}$, respectively. This suggested that the starch addition onto the metal oxides have minimal effect on the crystallite size.

Table. 1. Physical properties and DBT conversion of samples

\begin{tabular}{cccc}
\hline Samples & Crystallite size (nm) & Crystallinity (\%) & DBT conversion (\%) $^{\mathbf{1}}$ \\
\hline Starch & 5.6 & 21.5 & - \\
W-Mg-Al oxide & 38.7 & 57.2 & 48 \\
W-Mg-Al oxide-starch & 39.3 & 61.0 & 95 \\
\hline${ }^{1}$ reaction conditions: 0.1 g catalyst, $25 \mathrm{~mL} 200 \mathrm{ppm}$ DBT model fuel, $\mathrm{CH}_{3} \mathrm{COOH}: \mathrm{H}_{2} \mathrm{O}_{2}=1: 2(\mathrm{v} / \mathrm{v}), \mathrm{T}=80^{\circ} \mathrm{C}, \mathrm{t}=2 \mathrm{hours}$
\end{tabular}

The SEM micrographs of the samples are presented in Fig. 3. Fig. 3(a) shows that particle shapes of sago starch were granular shapes. The particles size ranges from 20 to $40 \mu \mathrm{m}$. W-Mg-Al oxide shows randomly distributed particles with variable sizes estimated to be in the range of 8 to $10 \mu \mathrm{m}$. Smaller particles in the range of 0.3 to $0.5 \mu \mathrm{m}$ were seen to be attached on these larger particles. The SEM image of $\mathrm{W}-\mathrm{Mg}$-Al oxide starch particles in Fig. 3(c) indicated that W-Mg-Al oxide successfully immobilised and well dispersed onto starch particles. The shapes of $\mathrm{W}-\mathrm{Mg}$-Al oxide on the starch surface was more uniform compared to $\mathrm{W}-\mathrm{Mg}$-Al oxide sample. The particle size of $\mathrm{W}-\mathrm{Mg}$-Al oxide starch were in the range of 0.3 to $0.8 \mu \mathrm{m}$. Therefore, the simple sol-gel method was successful in preparing W-Mg-Al oxide starch particles. Similar morphology is observed for both W-Mg-Al oxide and W-Mg-Al oxide starch, indicating similar crystalline phase which agrees with XRD pattern in Fig. 2. In addition, no residual granules of sago starch were observed in the $\mathrm{W}-\mathrm{Mg}$-Al oxide starch phase. Boiling water temperature during the preparation of $\mathrm{W}-\mathrm{Mg}$-Al oxide starch physically break the starch granules and disrupt the inter and intra molecular hydrogen bonds present. ${ }^{26} \mathrm{New}$ bond formed between starch and $\mathrm{W}-\mathrm{Mg}-\mathrm{Al}$ oxide distributes the $\mathrm{W}-\mathrm{Mg}$-Al oxide in the matrix. In the preparation of $\mathrm{W}-\mathrm{Mg}$ - 
$\mathrm{Al}$ oxide starch particles, the presence of soluble starch in the reaction medium quickly protected the formed oxide from further agglomeration. ${ }^{26}$ The $\mathrm{W}-\mathrm{Mg}$-Al oxide particles could not move freely, and they were dispersed uniformly in the network. The agglomerated W-Mg-Al oxide starch composite and the dispersed composite particles are both present in Fig. 3(c). The agglomeration of the composite was possibly due to the presence of starch during the drying process. ${ }^{25}$
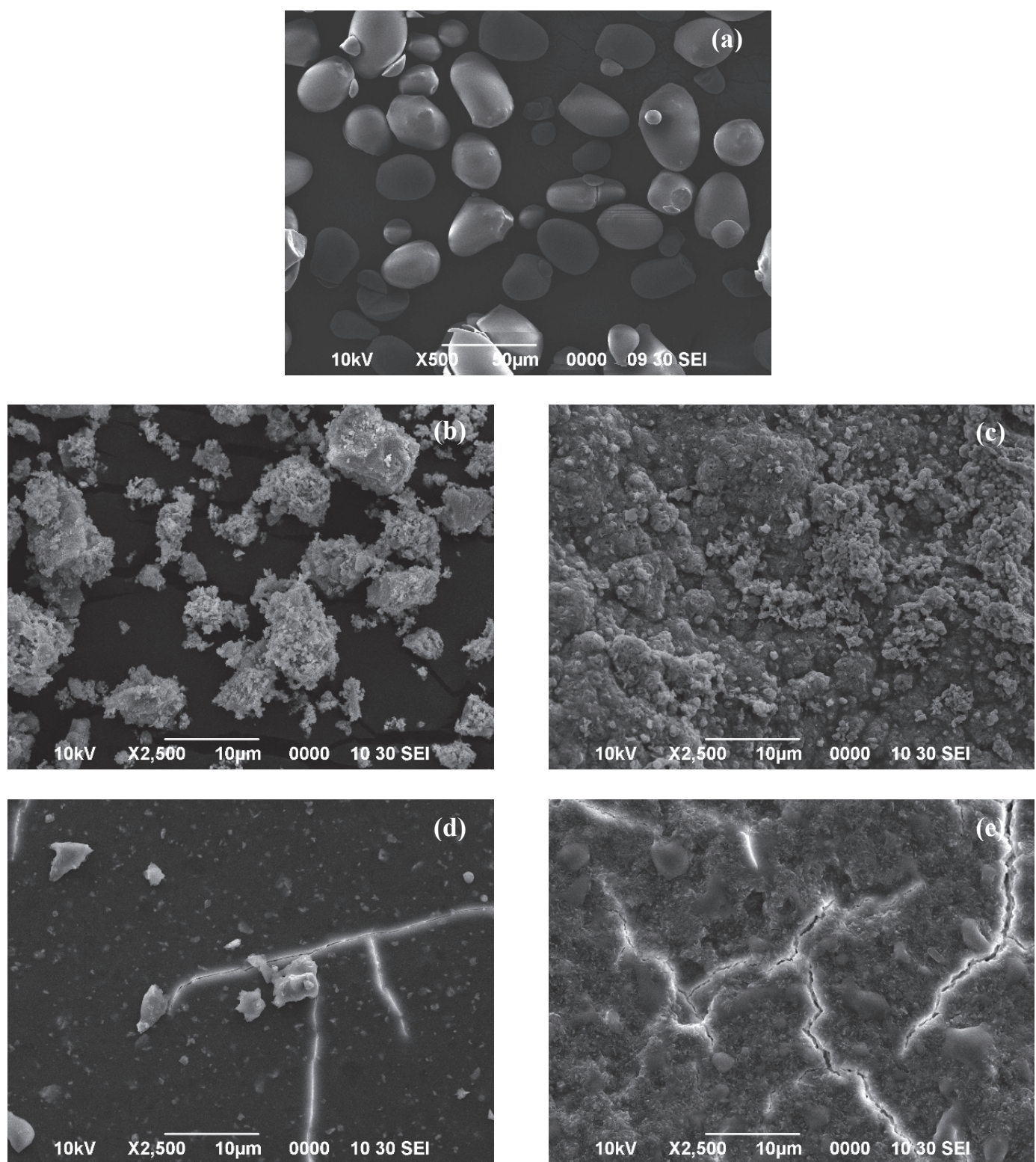

Fig. 3. SEM images of the samples (a) starch (b) W-Mg-Al oxide and (c) W-Mg-Al oxide starch (d) used W-Mg-Al oxide and (e) used W-Mg-Al oxide starch

The conversion of DBT for all samples during the ODS of DBT are reported in Table 1. Blank experiment was performed in the absence of catalyst with only pure starch. Under these conditions, DBT conversion was negligible in 2 hours. It was demonstrated that $\mathrm{W}-\mathrm{Mg}$-Al oxide and $\mathrm{W}-\mathrm{Mg}-\mathrm{Al}$ oxide starch actively catalysed the oxidative desulphurisation reaction under the same conditions. Despite having the same metal content of W-Mg-Al oxide, sample of W-Mg-Al oxide starch recorded the higher DBT conversion at $95 \%$ and selectivity at 100\% towards desulphurisation of DBT to DBTsulfone only. The initial concentration of $200 \mathrm{ppm}$ DBT identified by GC-MS at MW=184 was reduced to $10 \mathrm{ppm}$ DBT after 2 hours. As a comparison, W-Mg-Al oxide without starch reached $48 \%$ conversion. Dibenzothiophene sulfone, 4, 6-dimethyldodecane and tetracontane were the main 
desulphurisation products of DBT by $\mathrm{W}-\mathrm{Mg}-\mathrm{Al}$ oxide. The slight increase in conversion and higher selectivity of $\mathrm{W}-\mathrm{Mg}-\mathrm{Al}$ oxide starch compared to $\mathrm{W}-\mathrm{Mg}-\mathrm{Al}$ oxide was due to the higher crystallinity and dispersed active sites on the starch biopolymer. Therefore, $\mathrm{W}-\mathrm{Mg}-\mathrm{Al}$ oxide starch is identified as a more efficient catalyst for DBT. Hydrogen peroxide in the presence of organic acid such as acetic reacts in situ to produce peracid $\left(\mathrm{CH}_{3} \mathrm{COOOH}\right)$, which can efficiency convert organic sulphur to sulfones without forming a substantial amount of residual product. ${ }^{5}$ The role of the metal atoms in $\mathrm{W}$ $\mathrm{Mg}-\mathrm{Al}$ is to form peroxo-metal species which are able to activate the $\mathrm{H}_{2} \mathrm{O}_{2}$ and peracid molecules. W$\mathrm{Mg}$-Al active sites accepted the active oxygen from the oxidant $\mathrm{H}_{2} \mathrm{O}_{2}$ to form new oxoperoxo species mediate. The cation with carbon chain transferred oxoperoxo species to the substrates (DBT) and made the oxidation reaction accomplish completely. It was found that starch plays an important role in the formation of homogeneously dispersed nanoparticles. The pores on the surface of this particle could provide suitable place for trapping of sulphur containing compounds that participate in the oxidation reaction. Fig. 3(d) shows the SEM image of W-Mg-Al oxide after ODS reaction. Larger particles remained while smaller particles are no longer attached to the larger particles as observed in Fig. 3(b) before reaction. As for used W-Mg-Al oxide starch (Fig. 3(e)) after ODS, showed that the particles are still attached on the surface of starch. This suggest that the W-Mg-Al oxide starch catalyst has extra stability as compared to W-Mg-Al oxide. Since polysaccharides in starch could form complexes with metal ions due to their high number of functional groups (hydroxyl and glucoside groups) soluble starch could improve the stability ${ }^{26}$ of W-Mg-Al oxide starch sample.

\section{Conclusions}

A mixed oxide $\mathrm{W}-\mathrm{Mg}-\mathrm{Al}$ and $\mathrm{W}-\mathrm{Mg}-\mathrm{Al}$ immobilised on starch were successfully prepared by solgel method. The starch addition changed the oxide distribution to highly dispersed state which is attributed to the decomposition of starch in the high temperature. The addition of soluble starch to W$\mathrm{Mg}-\mathrm{Al}$ induced higher crystallinity which was conducive to the catalytic ODS of DBT which reached conversion of $95 \%$ under mild conditions. Starch modification has potential to effectively improve the physical property of metal oxides which will also improves the catalytic performances for desulphurisation.

\section{Acknowledgements}

The authors wish to gratefully acknowledge the financial support from Universiti Malaysia Sarawak under Special MyRA Assessment Funding C09/SpMYRA/1705/2018.

\section{Experimental}

\subsection{Materials and Methods}

All reagents were purchased from commercial sources and were used without further purification. Fourier-transform infrared spectroscopy (FTIR) spectra of the samples were recorded on Agilent Cary 630 spectrometer to identify chemical bonding and functional groups. X-ray Diffraction (XRD) patterns of the samples were obtained by D8 Advance (BRUKER AXS, Germany) diffractometer using $\mathrm{Cu} \mathrm{K} \alpha$ radiation $(\lambda=1.54056 \AA)$ from $10^{\circ}$ to $60^{\circ}$ to investigate the structural properties. Scanning Electron Microscope (SEM) images were taken using JSM-6390 (JEOL, USA) to identify the morphology and estimate the particle size of the samples.

\subsection{Preparation of samples}

\subsubsection{Preparation of $\mathrm{WO}_{3}$}

$\mathrm{WO}_{3}$ was prepared according to incipient wetness method with modifications. ${ }^{27}$ Typically, $0.5 \mathrm{~g}$ of tungstic acid was dissolved in $30 \mathrm{~mL}$ of oxalic acid aqueous solution $(1.87 \mathrm{~mol} / \mathrm{L})$ and heated at $50^{\circ} \mathrm{C}$ for 0.5 hour under stirring. The temperature was risen to $100^{\circ} \mathrm{C}$ for complete water evaporation. The resulting mixture was placed in an alumina crucible with a cover and calcined at $550^{\circ} \mathrm{C}$ under air atmosphere for 3 hours. 


\subsubsection{Preparation of $\mathrm{MgO}-\mathrm{Al}_{2} \mathrm{O}_{3}$ support}

$\mathrm{MgO}-\mathrm{Al}_{2} \mathrm{O}_{3}$ support was prepared by sol-gel method. ${ }^{11}$ Magnesium ethoxide was dissolved in 1propanol ( $1 \mathrm{~g}$ ethoxide/100 mol alcohol), and then stirred for 12 hours. Next, aluminium isopropoxide was added, then stirred for 12 hours. The mol ratio of $\mathrm{Mg}$ : $\mathrm{Al}$ is 4:1. The gel was obtained by hydrolysis with dropwise addition of deionized water. Then, the gel was dried at $100^{\circ} \mathrm{C}$ for 24 hours and then calcined at $550^{\circ} \mathrm{C}$ for 6 hours.

\subsubsection{Preparation of $W-M g-A l$ mixed oxide starch composite}

The W-Mg-Al mixed oxide starch composite was synthesized through the sol-gel method. ${ }^{28} \mathrm{~A}$ viscose solution was prepared by dissolving $0.10 \mathrm{~g}$ of sago starch in $40 \mathrm{~mL}$ of boiling distilled water. Then, $0.075 \mathrm{~g}$ of synthesized $\mathrm{WO}_{3}$ was added slowly to the solution and stirred vigorously at $65^{\circ} \mathrm{C}$ for 30 minutes. After homogenous dispersion of $\mathrm{WO}_{3}, 0.05 \mathrm{~g}$ of $\mathrm{MgO}-\mathrm{Al}_{2} \mathrm{O}_{3}$ powder was added to the mixture. The gel was aged at $80{ }^{\circ} \mathrm{C}$ for 2 hours. W-Mg-Al mixed oxide was also prepared without starch to investigate the role of starch.

\subsection{Catalytic oxidative desulphurisation (CODS) of dibenzothiophene}

The ODS catalytic tests were performed on the samples in a $25 \mathrm{~mL}$ flask equipped with a magnetic stirrer at an atmospheric pressure and $80^{\circ} \mathrm{C}$ as previously reported with modifications. ${ }^{29}$ Model fuel was prepared by dissolving DBT in $n$-heptane to make a stock solution with a sulphur concentration of $200 \mathrm{ppm}$. Then, $0.1 \mathrm{~g}$ of the catalyst was added to the flask followed by $3 \mathrm{~mL}$ of $\mathrm{CH}_{3} \mathrm{COOH}: \mathrm{H}_{2} \mathrm{O}_{2}$ in the ratio of $1: 2(\mathrm{v} / \mathrm{v})$ with stirring for 2 hours. Finally, the catalyst is separated from the reaction solution by centrifugation. Solvent extraction process was carried out using acetonitrile with acetonitrile:DBT in the ratio $1: 1(\mathrm{v} / \mathrm{v})$. Both oil phase and acetonitrile were placed in ultrasonic reactor for 30 minutes and left to settle at room temperature. The upper biphasic (oil phase) mixture was separated from acetonitrile by simple decantation. DBT concentration in the oil phase after the ODS process was analysed using Gas chromatography-mass spectroscopy (GC-MS) SHIDMADZU QP 5000 equipped with a flame ionization detector (FID) with helium as the carrier gas. The products in the oil phase was matched to mass spectrum with standard DBT and DBT-sulfone. The sulphur removal efficiency (X) of model oil was calculated by

$$
\mathrm{X}=\left(\mathrm{S}_{0}-\mathrm{S}\right) / \mathrm{S}_{0} \times 100 \%
$$

where $\mathrm{S}_{0}$ and $\mathrm{S}$ are the initial and final sulphur concentration of DBT, respectively.

\section{References}

1 Shen D., Dai Y., Han J., Gan L., Liu J., and Long M. (2018) A nanocellulose template strategy for the controllable synthesis of tungsten-containing mesoporous silica for ultradeep oxidative desulfurization. Chem. Eng. J., 332, 563-571.

2 Méndez F. J., Franco-López O. E., Bokhimi X., Solís-Casados D. A., Escobar-Alarcón L., and Klimova T. E. (2017) Dibenzothiophene hydrodesulfurization with NiMo and CoMo catalysts supported on niobium-modified MCM-41. Appl. Catal. B-Environ., 219, 479-491.

3 Sikarwar P., Kumar U. A., Gosu V., and Subbaramaiah V. (2018) Catalytic oxidative desulfurization of DBT using green catalyst (Mo/MCM-41) derived from coal fly ash, J. Environ. Chem. Eng., 6(2) 1736-1744.

4 Houda S., Lancelot C., Blanchard, P., Poinel, L., and Lamonier, C. (2018) Oxidative Desulfurization of Heavy Oils with High Sulfur Content: A Review. Catalysts, 8, 344.

5 Rezvani M. A., Oveisi M., and Asli M. A. N. (2015) Phosphotungestovanadate immobilized on PVA as an efficient and reusable nano catalyst for oxidative desulphurization of gasoline. J. Mol. Catal. A-Chem., 410, 121-132.

6 Otsuki S., Nonaka T., and Takashima N. (2000) Oxidative desulfurization of light gas oil and vacuum gas oil by oxidation and solvent extraction. Energ. Fuels, 14 (6) 1232-1239.

7 Rakhmanov E. V., Tarakanova A. V., Valieva T., Akopyan A. V., Litvinova V. V., Maksimov A. L., Anisimov A. V., Vakarin S. V., Semerikova O. L., and Zaikov Y. P. (2014) Oxidative desulfurization of diesel fraction with hydrogen peroxide in the presence of catalysts based on transition metals. Petrol. Chem+., 54 (1) 48-50. 
8 Zhao R., Li X., Su J., Shi W., and Gao X. (2017) Preparation of $\mathrm{WO}_{3} / \mathrm{C}$ composite and its application in oxidative desulfurization of fuel. China Pet. Process. Pe., 19 (2) 65-73.

9 Li X., Zhu H., Wang A., Wang Y., and Chen Y. (2013) Oxidative desulfurization of dibenzothiophene over tungsten oxides supported on $\mathrm{SiO}_{2}$ and $\gamma-\mathrm{Al}_{2} \mathrm{O}_{3}$. Chem. Lett., 42 (1) 8-10.

10 Ho T. C. (2004) Deep HDS of diesel fuel: chemistry and catalysis. Catal. Today, 98 (1-2) 3-18.

$11 \mathrm{Hu}$ Y. H., and Ruckenstein E. (2002) Binary MgO-based solid solution catalysts for methane conversion to syngas. Cataly. Rev., 44 (3) 423-453.

12 Guevara-Lara A., Cruz-Perez A. E., Contreras-Valdez Z., Mogica-Betancourt J., Alvarez-Hernandez A., and Vrinat M. (2010) Effect of Ni promoter in the oxide precursors of $\mathrm{MoS}_{2} / \mathrm{MgO}-\mathrm{Al}_{2} \mathrm{O}_{3}$ catalysts tested in dibenzothiophene hydrodesulphurization. Catal. Today, 149 (3-4) 288-294.

$13 \mathrm{Wu}$ L., Jiao D., Wang J., Chen L., and Cao, F. (2009) The role of MgO in the formation of surface active phases of $\mathrm{CoMo} / \mathrm{Al}_{2} \mathrm{O}_{3}-\mathrm{MgO}$ catalysts for hydrodesulfurization of dibenzothiophene. Catal. Commun., 11 (4) 302-305.

14 Vigneshwaran N., Kumar S., and Kathe, A. A. (2006) Functional finishing of cotton fabrics using zinc oxidesoluble starch nanocomposites. Nanotechnology, 17 (20) 5087-5095.

15 Lanje A. S., Sharma S. J., Ningthoujam R. S., Ahn J-S., and Pode R-B. (2013) Low temperature dielectric studies of zinc oxide ( $\mathrm{ZnO}$ ) nanoparticles prepared by precipitation method. Adv. Powder Technol., 24 (1) 331-335.

16 Chancharoenrith S., Kamonsatikul C., Namkajorn M., Kiatisevi S., and Somsook E. (2015) Iron oxide/cassava starch-supported Ziegler-Natta catalysts for in situ ethylene polymerization. Carbohyd. Polym., 117, 319-323.

17 Nouri L., and Mohammadi Nafchi A. (2014) Antibacterial, mechanical, and barrier properties of sago starch film incorporated with betel leaves extract. Int. J. Biol. Macromol., 66, 254-259.

18 Tao X., Liu D., Cong W., and Huang L. (2018) Controllable synthesis of starch-modified ZnMgAl-LDHs for adsorption property improvement. Appl. Surf. Sci., 457, 572-579.

19 Singh A., Guleria A., Neogy S., and Rath M. C. (2018) UV induced synthesis of starch capped CdSe quantum dots: Functionalization with thiourea and application in sensing heavy metals ions in aqueous solution. Arab. J. Chem., In Press (DOI: 10.1016/j.arabjc.2018.09.006)

20 Fang J. M., Fowler P. A., and Tomkinson J. (2002) The preparation and characterization of a series of chemically modified photo starches. Carbohyd. Polym., 47, 245-252.

21 Kizil R., Irudayaraj J., and Seetharaman, K. (2002) Characterization of irradiated starches by using FT-Raman and FTIR spectroscopy. J. Agric. Food Chem., 50 (14) 3912-3918.

22 Ding J., Liu Q., Zhang Z., Liu X., Zhao J., Cheng S., Zong B., and Dai W-L. (2015) Carbon nitride nanosheets decorated with $\mathrm{WO}_{3}$ nanorods: Ultrasonic-assisted facile synthesis and catalytic application in the green manufacture of dialdehydes. Appl. Catal. B-Environ., 165, 511-518.

23 Muthuselvi C., Arunkumar A., and Rajaperumal G. (2016) Growth and characterization of oxalic acid doped with tryptophan crystal for antimicrobial activity. Der Chemica Sinica, 7(4) 55-62.

24 Zhang H., Li Y., Duan G., Liu G., and Cai W. (2014) Tungsten oxide nanostructures based on laser ablation in water and a hydrothermal route. CrystEngComm., 16, 2491-2498.

25 Ma J., Zhu W., Tian Y., and Wang Z. (2016) Preparation of Zinc Oxide-Starch Nanocomposite and Its Application on Coating. Nanoscale Res. Lett., 11, 200.

26 Ma X., Chang P. R., Yang J., and Yu J. (2009) Preparation and properties of glycerol plasticized-pea starch/zinc oxide-starch bionanocomposites. Carbohyd. Polym., 75, 472-478.

27 Ding J., Liu Q., Zhang Z., Liu X., Zhao J., Cheng S., and Zong B., Dai, W-L. (2015) Carbon nitride nanosheets decorated with $\mathrm{WO}_{3}$ nanorods: Ultrasonic assisted facile synthesis and catalytic application in the green manufacture of dialdehydes. Appl. Catal. B-Environ., 165, 511-518.

28 Rezvani M. A., Shaterian M., Akbarzadeh F., and Khandan S. (2018) Deep oxidative desulfurization of gasoline induced by $\mathrm{PMoCu} @ \mathrm{MgCu}_{2} \mathrm{O}_{4}-\mathrm{PVA}$ composite as a high-performance heterogeneous nanocatalyst. Chem. Eng. $J ., 333,537-544$.

29 Rezvani M. A., Khandan S., and Aghmasheh M. (2017) Synthesis and characterization of new nanocomposite TBA-PW11 Ni@NiO as an efficient and reusable heterogeneous catalyst in oxidative desulphurization of gasoline. J. Taiwan Inst. Chem. E., 77, 321-328.

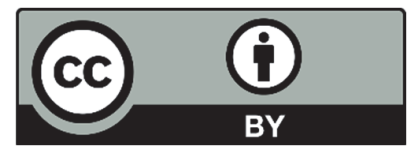

C 2020 by the authors; licensee Growing Science, Canada. This is an open access article distributed under the terms and conditions of the Creative Commons Attribution (CC-BY) license (http://creativecommons.org/licenses/by/4.0/). 